\title{
Research Article: Correlation studies of guava graft compatibility and its growth performance in relation with different nature of scion
}

\section{U.R. RESHMA, S.G. BHARAD AND KUNTAL SATKAR}

Article Chronicle: Received :

10.07.2017;

Accepted :

25.07.2017

KeY WORDS:

Guava, Grafting performance, Scion, Correlation

Author for correspondence :

\section{U.R. RESHMA}

Department of

Horticulture, Dr.

Panjabrao Deshmukh

Krishi Vidyapeeth,

AKOLA (M.S.) INDIA

Email : ur.reshu@

gmail.com

See end of the article for

authors' affiliations
SUMMARY : In order to investigate the influence of nature of scion on graft success, subsequent growth of scion shoot and development of the successful grafts in guava, a field experiment was carried out in Nursery unit of Dr. P.D.K.V, Akola during the year 2015-16.The results were obtained for the correlation co-efficient. The correlation co-efficient indicates the presence of inherent association between various characters. The final survival of guava grafts were positively and significantly correlated with days required for bud sprouting $\left(\mathrm{r}=0.845^{* *}\right)$, graft take percentage $\left(\mathrm{r}=0.970^{* *}\right)$, scion length $\left(\mathrm{r}=0.956^{* *}\right)$ number of leaves $\left(\mathrm{r}=0.984^{* *}\right)$ and leaf area $\left(\mathrm{r}=0.809^{*}\right)$ in relation with green quadrangular terminal shoot used as scion, while final survival was negatively associated with days required for sprouting when the brown corky shoot concerned.

How to cite this article : Reshma, U.R., Bharad, S.G. and Satkar, Kuntal (2017). Correlation studies of guava graft compatibility and its growth performance in relation with different nature of scion. Agric. Update, 12(TECHSEAR-3) : 743-748; DOI: 10.15740/HAS/AU/12.TECHSEAR(3)2017/743-748. 